This is a repository copy of "Adaptive incremental state space MPC for collector defocusing of a parabolic trough plant" in the Depósito de Investigación de la Universidad de Sevilla

Version: Author Accepted Version

Citation: A.J. Sánchez, A.J. Gallego, J.M. Escaño \& E.F. Camacho. "Adaptive incremental state space MPC for collector defocusing of a parabolic trough plant". Solar Energy - ISSN 0038-092X. Vol. 184, pp. 105-114. Mayo 2019. 10.1016/.solener.2019.03.094

To cite this publication, please use the final published version (if applicable). Please check the document version above.

Copyright: Other than for strictly personal use, it is not permitted to download, forward or distribute the text or part of it, without the consent of the author(s) and/or copyright holder(s), unless the work is under an open content license such as Creative Commons.

Takedown policy: Please contact us (idus@us.es) and provide details if you believe this document breaches copyrights. We will remove access to the work immediately and investigate your claim 


\title{
Adaptive Incremental State Space MPC for collector defocusing of a parabolic trough plant
}

\author{
A.J. Sánchez ${ }^{\mathrm{a}, *}$, A.J. Gallego ${ }^{\mathrm{a}}$, J.M. Escaño ${ }^{\mathrm{a}}$, E.F. Camacho ${ }^{\mathrm{a}}$ \\ ${ }^{a}$ Departamento de Ingeniería de Sistemas y Automática, Universidad de Sevilla, Camino de los Descubrimientos s/n, 41092 Sevilla, Spain
}

\begin{abstract}
Commercial solar plants produce energy around a nominal operating point in which the solar field outlet temperature is high and close to the thermal limit of the heat transfer fluid. The main control of the temperature is carried out by means of the fluid flow-rate that circulates through the solar field. Defocusing the collectors is normally used as a safety mechanism to avoid exceeding the thermal limit. However, in situations in which the flow is saturated, the control of defocusing the collectors becomes of vital importance and is the system in charge of controlling the solar field outlet temperature.

The paper presents an Adaptive State Space Model Predictive Control strategy with an incremental formulation to control the fourth and third collector defocus angles for field outlet temperature set-point tracking at the nominal operation point, avoiding the Heat Transfer Fluid temperature from exceeding the manufacturer thermal limit (oil degradation). The state space description uses an Unscented Kalman Filter for estimating the non-measurable states. A 50 MW parabolic solar trough plant nonlinear model has been used to design and validate the strategy. Simulation results are presented showing the advantages of using the proposed strategy.
\end{abstract}

Keywords: Solar Energy, Model Predictive Control, Collector defocus, Electric power limitation

\section{Introduction}

Interest in the research and development of renewable energies is currently increasing. The main reason is concern about global warming. That is, the reason nowadays for promoting the use of renewable energies is to reduce harmful emissions from conventional fossil power plants and, therefore, their environmental impact (Blanco and Santigosa, 2017). Hydro, solar and wind energies are the renewable energy sources that are currently being exploited. However, solar energy is by far the most abundant renewable energy. This paper focuses on thermal solar trough plants.

Some examples of commercial Concentrating Solar Power (CSP) plants with Parabolic Trough Collectors (PTC) that have been built in the last decade are: Solaben CSPs 50 MW (1/2/4/6, total of $200 \mathrm{MW}$ and 220 hectares, 90 loops each) (Solaben 2, 2018) in Spain, Mojave CSPs 140 MW (I/II, total of $280 \mathrm{MW}$ and 714 hectares) in the United States (Mojave Solar Project, 2018), and Kaxu Solar One 100 MW (Kaxu Solar One, 2018) in South Africa. One of the most important characteristics of CSP plants is the possibility of storing energy by means of a thermal energy storage (Liu et al., 2016; Alva et al., 2017; Pelay et al.,

\footnotetext{
*Corresponding author Tel.: +34 600064314

Email addresses: asanchezdelpozo@us.es (A.J. Sánchez), gallegolen@hotmail.com (A.J. Gallego), jmesca@ieee.org (J.M. Escaño), ef camacho@us.es (E.F. Camacho)
}

2017; Sarbu and Sebarchievici, 2018). Generally, this is done by using molten salt tanks (hot and cold) (Roca et al., 2016; Solana Generating Station, 2018; Termesol 50, 2018).

Typically, the main objective when controlling solar trough plants is to maintain the outlet temperature of the field around a desired set-point. Unlike conventional fossil fuel plants where the main source of energy (fuel) can be manipulated, in solar plants, the main source of energy is considered a disturbance since the plant controller has to deal with radiation transients due to clouds and the daily beam radiation profile.

In the literature, research works mainly focus on new control methods for temperature tracking, stability, constraints, and optimization of the plant to name just a few. Model Predictive Control (MPC) is one of the most applied techniques to improve temperature set-point tracking. Some examples are: Gil et al. (2014) where a Neural Network based MPC is presented; in Khoukhi et al. (2015), authors presented nonlinear continuous-time Generalized Predictive Control (GPC) of solar plants, while in Lima et al. (2016), an MPC is designed based on Filtered Dynamic Matrix Control (FDMC); in Alsharkawi and Rossiter (2017), an improvement of a dual Gain Scheduling GPC by including a Feed Forward (FF) for disturbance rejection is presented.

Regarding plant optimization, most of the effort has been focused on cost reduction and power optimization 
(N.A Engineering, 2008; Blanco and Miller, 2017). Amongst others can be found Camacho and Gallego (2013) an optimization is proposed to obtain the optimal working temperature throughout the day, taking into account the solar field efficiency. An extensive energy and economic analysis is presented in Desai and Bandyopadhyay (2015), in which optimal turbine inlet pressure is proven to be a weak function of design radiation. He et al. (2016) develops a general model framework to optimize the offering strategy for CSP plants in joint day-ahead energy, reserve and regulation markets. In Vasallo and Bravo (2016) a modelbased predictive control (MPC) strategy to optimize the scheduling in CSP plants usings short-term direct normal irradiance forecast is proposed. In Sánchez et al. (2018b) field temperature homogenization is achieved by means of online, non-linear, model based optimization, since loop efficiency may differ due to mirror dirt. By homogenizing the field, electric power improvements are obtained. In Cojocaru et al. (2019) authors proposed a scheduling strategy for CSP with thermal energy storage based on a mixed-integer linear programming model which approximates the plant operation.

Nevertheless, there are situations in which tracking the field outlet temperature set-point just by controlling the flow-rate becomes impossible. This mainly occurs when the plant is in two situations: (1) saturation, (2) power limitation. In saturation, the plant has reached the limit of solar energy that it is capable of processing to generate the nominal power of the plant. In this case, the plant has reached the maximum oil flow-rate; therefore, there is no more control capability and the field outlet temperature will increase. In the second situation, the plant is forced by the Transmission System Operator (TSO) to reduce the generated net power. Typically, when the electrical grid is saturated, the plant will have a period in which to reduce its generated electric power to a set-point determined by the TSO. If the directive ordered by the TSO is not complied with, the plant will face economic sanctions. To decrease power, it is necessary to decrease the oil flow-rate that reaches the heat exchanger where the steam phase begins. This situation is similar to saturation, since the variable controlling the outlet field temperature (flow-rate) has been limited. As in saturation, the outlet temperature will inevitably increase. Plants with Thermal Energy Storage (TES) are able to deal with these situations, at least for a while, by diverting part of the flow-rate to the TES until these are saturated. Plants with no TES cannot cope with this so easily. This work focuses on plants that do not have TES, such as the ones described in Guzmán (2018) and Solaben 2 (2018).

To prevent the temperature from exceeding the degradation limit, commercial plants have a safety strategy: collector defocus. This is applied in a staggered manner as total or partial defocusing. Given that it is proposed as a safety mechanism, it is highly inefficient due to the thermal jumps caused by the application of full or partial defocusing. Since it is usually carried out only on the basis of thresholds, the mechanism of defocusing is reactive and may cause oscillations in the outlet temperature of the loops.

In this paper, an Adaptive Incremental State Space Model Predictive Control (MPC) is proposed for defocusing the fourth and third collectors in order to control the loop outlet temperature, thus avoiding the loop temperature from exceeding the degradation limit temperature, since the flow-rate control will not be available in saturation and power limitation events. The state space estimation is done by means of an Unscented Kalman Filter (UKF) which uses a nonlinear model to estimate the states. Since the loops may differ, due to dust for example, an estimation of the efficiency is obtained by means of the lumped parameter model to adapt the MPC model to the real collector state. To design and simulate the control strategy, a $50 \mathrm{MW}$ parabolic trough plant model is used.

There are very few works related to controlling the temperature by using the defocus angle of the collector. In Elias et al. (2018), authors presented a preliminary study to defocus solar collectors to prevent the fluid outlet temperature from exceeding the maximum temperature. The control is done by means of a Mixed Logical Dynamical (MLD) model and a Practical Nonlinear Model Predictive Controller (PNMPC) where the manipulated variable is a defocus binary angle, zero or full collector defocus. In Sánchez et al. (2018a), the authors presented an Event based Gain Scheduling Model Predictive Control (GS-GPC) for defocusing the fourth and third collectors and power control. In this work, authors opted for a strategy of temperature tracking at the outlet of the collectors instead of working in a reactive manner based on a maximum threshold. The strategy is developed to work both in saturation and power limitations. Although the GS-GPC provides good results in simulations, it is a controller based on linear models calculated at different working points. Therefore, its performance may be affected since it is based on linear models. As shown in section 6 , the proposed control strategy outperforms the one proposed in Sánchez et al. (2018a).

The main advantages of the proposed control scheme, with respect to the strategies already proposed, are:

1. The state space formulation permits the model to adapt to the plant state each sampling time because many coefficients depend on temperature and flowrate such as: heat transmission coefficient, global thermal losses, density, to name but a few.

2. With the incremental formulation, the disturbance estimator is not needed.

3. Estimation of the efficiency of the collectors.

This paper is organized as follows: In section 2 the $50 \mathrm{MW}$ solar plant model is described. In section 3 , the flow-rate Gain Scheduling Generalized Predictive Control scheme (GS-GPC) is explained as well as a series FeedForward $(\mathrm{FF})$. In section 4, electric power EGS-GPC is 
briefly described. In section 5, the fourth collector and third collector MPCs are presented as well as the UKF state estimation and collector loop efficiency estimation. Simulation results are presented in section 6 . Finally, in section 7 , the paper draws to a close with some concluding remarks and future work.

\section{Parabolic trough field model}

Most of the Research works have used the ACUREX solar plant model for designing and testing. The ACUREX field, located at the Plataforma Solar de Almería, consists of 480 parabolic trough collectors arranged in 10 loops with a total length of $172 \mathrm{~m}$. In order to correctly simulate the defocus strategy in saturation and power limitation events, a 50 MW plant model, based on Helios I (Guzmán, 2018; Helios I, 2018; Ibersol Ciudad Real, 2018), is used in this paper to design and simulate the proposed MPC strategy. To simulate the $50 \mathrm{MW}$ solar plant, a distributed parameter model is used (Camacho et al., 1997).

\subsection{Parabolic trough field}

The solar field of a 50 MW plant occupies around 220 hectares. The total length of each loop is $600 \mathrm{~m}$ with 4 collectors to each loop (Extresol-1, 2018; Guzmán, 2018; Solaben 2, 2018). In commercial plants, the number of loops is 80-100 loops (Guzmán, 2018; Helios I, 2018; Ibersol Ciudad Real, 2018; Majadas I, 2018; Palma del Río I, 2018; Solaben 2, 2018). The plant model chosen to design and simulate the proposed strategy consists of 90 loops. Each loop is composed of four collectors (150 meters each). Fig. 1 presents the layout of a parabolic trough plant. The plant model is assumed to have a north-south orientation. Generally, this is the most common orientation in commercial solar plants for efficiency reasons.

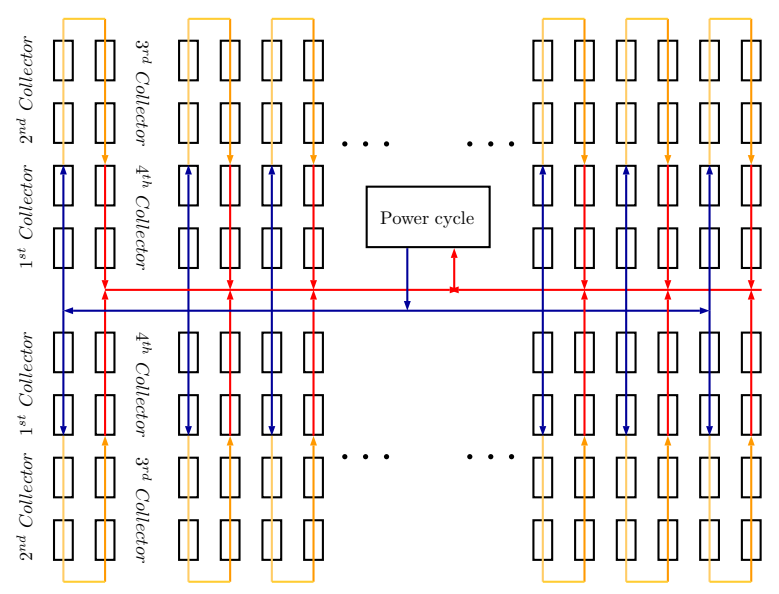

Figure 1 Parabolic trough plant layout

\subsection{Collector, receiver tube and heat transfer fluid}

For the simulation model of this paper, the collector EuroTrough ET150 (Rohani et al., 2017; Andasol 1, 2018;
System Advisor Model (SAM). NREL, 2018) has been selected. In order to simulate the field, it is necessary to describe the collector in terms of parameters such as focal length, aperture width and collector length. For all EuroTrough ET150 parameter descriptions and values refer to Geyer et al. (2002), Kearney (2007), System Advisor Model (SAM). NREL (2018).

One of the receiver tubes most used in commercial plants (Andasol 1, 2018; Extresol-1, 2018; Ibersol Ciudad Real, 2018) is the Schott PTR 70. A full description of Schott PTR70 can be found in SCHOTT Solar CSP $\mathrm{GmbH}$ (2018). For this paper, the maximum values for the collector reflectivity, tube efficiency and shape factor have been assumed to be $0.91,0.91$ and 0.96 respectively.

The Heat Transfer Fluid (HTF) is specifically developed for the indirect transfer of process heat. In this paper, Therminol VP1 is used. The optimum range for operation is between $12{ }^{\circ} \mathrm{C}$ and $400{ }^{\circ} \mathrm{C}$ (Therminol VP1 HTF, 2018). Above $400{ }^{\circ} \mathrm{C}$ the fluid starts to degrade. Fluid density $\left(\rho_{f}\right)$ and specific heat capacity $\left(C_{f}\right)$ are temperature dependent and can be obtained by equations (1) and (2). For more parameter approximations, refer to Therminol VP1 HTF (2018).

$$
\begin{array}{r}
\rho_{f}=-0.90797 \cdot T+0.00078116 \cdot T^{2}-2.367 \times 10^{-6} \cdot T^{3} \\
+1083.25
\end{array}
$$

The power generation is proportional to the oil flowrate and the HTF temperature drop (Temperature of the hot HTF minus the temperature of the cold HTF returning to the solar field) at the steam generator. This temperature drop is approximately $90-100{ }^{\circ} \mathrm{C}$ in current plants with an outlet temperature of around $393{ }^{\circ} \mathrm{C}$ and field inlet temperature of $293{ }^{\circ} \mathrm{C}$ at nominal operation. In this paper an efficiency of the Rankine cycle of 0.381 (Andasol 1, 2018; Extresol-1, 2018)) is used as well as an exchanger efficiency of 0.9 and parasitic effects, typically 0.9 , which reduce the generated power and therefore there is a gross and a net power (System Advisor Model (SAM). NREL, 2018). Finally, under nominal operation (inlet temperature of $293{ }^{\circ} \mathrm{C}$, outlet temperature of $393{ }^{\circ} \mathrm{C}$ approximately) the HTF flow-rate needed to produce $50 \mathrm{MW}$ is $3350 \mathrm{~m}^{3} / \mathrm{h}$, approximately, using equation 3, (Sánchez et al., 2018a).

$$
Q=\frac{P \cdot 10^{6}}{\Delta T \cdot C_{f} \cdot \mu_{\text {rank }} \cdot \mu_{e x} \cdot \mu_{\text {paras }}}
$$

To simulate the power at each instant, equation 3 is used. The calculated power is then filtered applying a first order transfer function depending on the flow-rate (Schenk et al., 2015; Montañés et al., 2018). 


\section{Nomenclature}

\begin{tabular}{|c|c|c|c|}
\hline$A$ & Cross-sectional area of the pipe $\left(\mathrm{m}^{2}\right)$ & $t$ & Time (s) \\
\hline$C(t, T)$ & Specific heat capacity $\left(\mathrm{J} /\left(\mathrm{kg}^{\circ} \mathrm{C}\right)\right)$ & $T(x, t)$ & Temperature $\left({ }^{\circ} \mathrm{C}\right)$ \\
\hline$D$ & Hydraulic diameter of the pipe $(\mathrm{m})$ & $T_{a}(t)$ & Ambient temperature $\left({ }^{\circ} \mathrm{C}\right)$ \\
\hline$G$ & Collector aperture (m) & $T_{C 3}^{i}$ & Third collector temperature (loop $i)\left({ }^{\circ} \mathrm{C}\right)$ \\
\hline$H_{l}(t, T)$ & $\begin{array}{l}\text { Thermal loss global coefficient } \\
\left(\mathrm{W} /\left(\mathrm{m}^{2} \mathrm{C}\right)\right)\end{array}$ & $T_{i n}$ & Inlet temperature $\left({ }^{\circ} \mathrm{C}\right)$ \\
\hline$H_{t}(t, T, q)$ & $\begin{array}{l}\text { Metal-fluid heat transmission coefficient } \\
\left(\mathrm{W} /\left(\mathrm{m}^{2} \mathrm{C}\right)\right)\end{array}$ & $T_{\text {out }}$ & Outlet temperature $\left({ }^{\circ} \mathrm{C}\right)$ \\
\hline$I(t)$ & Direct solar radiation $\left(\mathrm{W} / \mathrm{m}^{2}\right)$ & $T_{\text {mean }}$ & $\begin{array}{l}\text { Mean temperature between inlet and } \\
\text { outlet temperature }\left({ }^{\circ} \mathrm{C}\right)\end{array}$ \\
\hline$k(t, T)$ & Thermal conductivity $\left(\mathrm{W} /\left(\mathrm{m}^{\circ} \mathrm{C}\right)\right)$ & $T_{\text {set-point }}$ & Temperature reference for tracking $\left({ }^{\circ} \mathrm{C}\right)$ \\
\hline$K_{o p t}$ & Optical efficiency (Unitless) & $T_{r e f-C 3}$ & $\begin{array}{l}\text { Temperature set-point applied } \\
\text { to the } 3^{r d} \text { collector }\left({ }^{\circ} \mathrm{C}\right)\end{array}$ \\
\hline$L$ & Length of pipeline $(\mathrm{m})$ & $T_{r e f-C 4}$ & $\begin{array}{l}\text { Temperature set-point applied } \\
\text { to the } 4^{t h} \text { collector }\left({ }^{\circ} \mathrm{C}\right)\end{array}$ \\
\hline$n_{o}(t)$ & Geometric efficiency (Unitless) & $T_{\text {ref-sat }}$ & $\begin{array}{l}\text { Temperature set-point for the } 4^{t h} \\
\text { collector in saturation }\left({ }^{\circ} \mathrm{C}\right)\end{array}$ \\
\hline$N u$ & Nusselt number & $T_{r e f-n o s a t}$ & $\begin{array}{l}\text { Temperature set-point for the } 4^{t h} \\
\text { collector not in saturation }\left({ }^{\circ} \mathrm{C}\right)\end{array}$ \\
\hline$P$ & Power (MW) & $x$ & Space $(\mathrm{m})$ \\
\hline$P_{c p}$ & $\begin{array}{l}\text { Fixed factor (loop geometrical and thermal } \\
\text { properties) }\end{array}$ & $\Delta T$ & Thermal difference $\left({ }^{\circ} \mathrm{C}\right)$ \\
\hline phi & Fixed factor (Unitless) & $\beta_{k}^{i}$ & $\begin{array}{l}\text { Defocus angle, } 4^{\text {th }} \text { collector, loop } i \\
\text { instant } \mathrm{k} \text { (deg) }\end{array}$ \\
\hline $\operatorname{Pr}$ & Prandtl number & $\gamma_{k}^{i}$ & $\begin{array}{l}\text { Defocus angle, } 3^{\text {th }} \text { collector, loop } i \\
\text { instant } \mathrm{k} \text { (deg) }\end{array}$ \\
\hline$Q(t)$ & Solar field oil flow rate $\left(\mathrm{m}^{3} / \mathrm{h}, \mathrm{kg} / \mathrm{s}\right)$ & $\mu(t, T)$ & $\begin{array}{l}\text { Dynamic viscosity of the fluid } \\
(\mathrm{Pa} \cdot \mathrm{s}=\mathrm{N} \cdot \mathrm{s} / \mathrm{m} 2=\mathrm{kg} /(\mathrm{m} \cdot \mathrm{s}))\end{array}$ \\
\hline$q(t)$ & Loop oil flow rate $\left(\mathrm{m}^{3} / \mathrm{s}\right)$ & $\mu_{c o l}(t, T)$ & Collector defocus efficiency (Unitless) \\
\hline$q_{f f}$ & $\begin{array}{l}\text { Computed flow-rate by the } \\
\text { Feed Forward }\left(\mathrm{m}^{3} / \mathrm{s}\right)\end{array}$ & $\nu(t, T)$ & Kinematic viscosity $\left(\mathrm{m}^{2} / \mathrm{s}\right)$ \\
\hline$R e$ & Reynolds number & $\rho(t, T)$ & Density $\left(\mathrm{kg} / \mathrm{m}^{3}\right)$ \\
\hline$S$ & Total reflective surface $\left(\mathrm{m}^{2}\right)$ & & \\
\hline
\end{tabular}

\subsection{Distributed parameter model}

The dynamics of the distributed solar collector field are described by the system of partial differential equations (PDE) given in equation 4 . These equations describe the energy balance in the system (Carmona, 1985; Camacho et al., 1997):

$$
\begin{aligned}
& \rho_{m} C_{m} A_{m} \frac{\partial T_{m}}{\partial t}=I K_{o p t} n_{o} G-H_{l} G\left(T_{m}-T_{a}\right)-L H_{t}\left(T_{m}-T_{f}\right) \\
& \rho_{f} C_{f} A_{f} \frac{\partial T_{f}}{\partial t}+\rho_{f} C_{f} q \frac{\partial T_{f}}{\partial x}=L H_{t}\left(T_{m}-T_{f}\right)
\end{aligned}
$$

where the subindex $m$ refers to the metal and $f$ refers to the fluid. The geometric efficiency depends on hourly angle, solar hour, declination, day of the year, local lat- 
itude and collector dimensions. The density $\rho$, specific heat $C$ and coefficients $H_{t}$ and $H_{l}$ depend on fluid temperature. $H_{t}$ also depends on the HTF flow-rate (Camacho et al., 1997). $H_{t}$ can be calculated with the equations (5) (Therminol VP1 HTF, 2018) and $H_{l}$ can be obtained from Burkholder et al. (2007), Lüpfert et al. (2008).

$$
\begin{aligned}
& R e=q \cdot D /(\nu \cdot A) \\
& \operatorname{Pr}=C_{f} \cdot \mu / k \\
& N u=0.025 \cdot\left(\operatorname{Re}^{0.79}\right) \cdot\left(\operatorname{Pr}^{0.42}\right) \cdot p h i \\
& H_{t}=N u \cdot k / D
\end{aligned}
$$

where $k, \mu$ and $\nu$ (VP1 parameters) are temperature dependent (Therminol VP1 HTF, 2018). The model discretization is done along the longitudinal dimension of the tube. In this manner, a chain of sub-models is used to simulate the dynamics of each loop. The loops are divided into 300 segments of approximately 2 meters in length. This length of segment provides good simulation performance and low computation times (Sánchez et al., 2018a).

\subsection{Lumped parameter model}

The Lumped parameter model (LPM) provides a general description of the whole field. This model describes the variation in the internal energy of the fluid by equation 6. This model will be used to implement a series Feed-Forward control and to estimate the collector global efficiency.

$C_{\text {loop }} \frac{d T_{\text {out }}}{d t}=K_{\text {opt }} n_{o} S I-q P_{c p}\left(T_{\text {out }}-T_{\text {in }}\right)-H_{l} S\left(T_{\text {mean }}-T\right.$

where $P_{c p}$ can be approximated by $1.868 \times 10^{6} \mathrm{~J} / \mathrm{m}^{3} \mathrm{C}$, $C_{\text {loop }}$ is approximated by $3.287 \times 10^{6} \mathrm{~J} /{ }^{\circ} \mathrm{C}$ and $S$ is equal to $3427 \mathrm{~m}^{2}$ (Sánchez et al., 2018a).

\section{Flow-Rate MPC control scheme}

This section describes the control scheme used to perform the outlet temperature tracking. A GS-GPC is used for the flow-rate control scheme and a series FF is used for disturbance rejection. The series FF has proven to be very effective at rejecting measurable disturbances affecting the solar field. (Camacho et al., 1997).

\subsection{Generalized Predictive Control}

The GPC algorithm is based on the CARIMA model (single-input single-output model) (Camacho and Bordons, 2007):

$$
A\left(z^{-1}\right) y_{k}=z^{-d} B\left(z^{-1}\right) u_{k-1}+\frac{C\left(z^{-1}\right)}{\Delta} e_{k}
$$

where $u_{k}$ and $y_{k}$ are the control and output sequences of the plant, $e_{k}$ is a zero mean white noise term, $d$ is the dead time of the system and $\Delta$ is the integrator operator. $A, B$ and $C$ are polynomials in the backward shift operator $z^{-1}$ (Camacho and Bordons, 2007). Consider a multistage cost function of the form:

$$
\begin{array}{r}
J\left(N_{1}, N_{2}, N_{u}\right)=\sum_{j=N_{1}}^{N_{2}} \delta(j)[\hat{y}(k+j \mid k)-w(k+j)]^{2} \\
+\sum_{j=1}^{N_{u}} \lambda(j)[\Delta u(k+j-1)]^{2}
\end{array}
$$

where $\hat{y}(k+j \mid k)$ is an optimum $\mathrm{j}$ step ahead prediction of the system output, $N_{1}$ and $N_{2}$ are the minimum and maximum costing horizons, $N_{u}$ is the control horizon, $\delta(j)$ and $\lambda(j)$ are weighting sequences and $w(k+j)$ is the future reference trajectory. The future reference trajectory is either constant or variable in case there is a previous knowledge of the set-point the plant/operator is going to apply. Since solar plants have to deal with ambient perturbations, there is no usually previous knowledge for the future field outlet temperature set-points and therefore is set to a constant value. Moreover, in saturation, the applied future reference trajectory is constant at 393 ${ }^{\circ} \mathrm{C}$ since is the nominal operating point. The aim of GPC is to minimise $J\left(N_{1}, N_{2}, N_{u}\right)$ in order to compute a future sequence of control actions $u(k), u(k+1), \cdots, u\left(k+N_{u}\right)$ that drives the future plant output $y(k+j)$ close towards $w(k+j)$. Hence, given a CARIMA plant model and suitable cost function, the minimum of the cost function can be obtained by setting the gradient of $\mathbf{J}$ equal to zero and $T_{a}$ solving the control sequence $\Delta \mathbf{u}$ by the following equation (Camacho and Bordons, 2007):

$$
\Delta \mathbf{u}=\left(\mathbf{G G}^{T}+\lambda \mathbf{I}\right)^{-1} \mathbf{G}^{T}(\mathbf{w}-\mathbf{f})
$$

where matrix $\mathbf{G}$ contains the step response coefficients of the forced response model (Camacho et al., 2012), I is the eye matrix, $\mathbf{f}$ is the free response of the plant, $\mathbf{w}$ is the future reference trajectory vector and $\lambda$ is the control weighting vector (Camacho and Bordons, 2007), being $\delta=$ 1 and $\lambda=10$.

\subsection{Gain Scheduling}

The design of the GS-GPC is described in Camacho et al. $(1994,1997)$. The GS-GPC controller has demonstrated to have very good behaviour not only in respect to set-point tracking but also in disturbance rejection capabilities (Camacho et al., 1997). Depending on the point at which the system operates, the GS-GPC feedback gain is adjusted in order to compensate variation in the plant response under different working conditions. In a solar trough plant, dynamics are mainly dictated by the oil flow. Suitable identification of linear models at four different setpoints for the oil flow-rate covering the operation range, (1494, 1908, 2322 and $2736 \mathrm{~m}^{3} / \mathrm{h}$ ), will be used (Sánchez et al., 2018a). The linear models have been obtained by 
applying a PRBS signals with $T_{i n}=293, I=600$ and $T_{a}=293$, to obtain the models at each flow-rate. The linear models obtained describe the plant dynamics in a global manner. The discrete-time transfer functions have been chosen as indicated in Eq. (10) and Table 1 shows the parameter of linear models for the considered HTF flow-rate operating point. For the gain scheduling transitions, intermediate values have been deduced by linear interpolation (Camacho et al., 1997).

$$
G=\frac{b_{0} z^{-1}+b_{1} z^{-2}+b_{2} z^{-3}+b_{3} z^{-4}}{1+a_{0} z^{-1}+a_{1} z^{-2}+a_{2} z^{-3}+a_{3} z^{-4}}
$$

Table 1

Flow Linear model parameters depending on the HTF flow $\left(\mathrm{m}^{3} / \mathrm{h}\right)$

\begin{tabular}{lllll}
\hline $\mathrm{Q}$ & 1494 & 1908 & 2322 & 2736 \\
\hline$b_{0}$ & 0.01388 & 0.01198 & 0.03897 & 0.04289 \\
\hline$b_{1}$ & -0.01376 & -0.002375 & -0.02267 & -0.005028 \\
\hline$b_{2}$ & 0.005233 & 0.004182 & 0.01313 & 0.01046 \\
\hline$b_{3}$ & 0.005655 & 0.006583 & 0.009729 & 0.01582 \\
\hline$a_{0}$ & -2.025 & -2.035 & -1.972 & -1.802 \\
\hline$a_{1}$ & 1.105 & 1.317 & 1.311 & 1.132 \\
\hline$a_{2}$ & 0.03021 & -0.2882 & -0.3369 & -0.3352 \\
\hline$a_{3}$ & -0.09569 & 0.03236 & 0.03794 & 0.07595 \\
\hline
\end{tabular}

\subsection{Series Feed-Forward}

The use of a series Feed-Forward controller action has proven to be very effective at rejecting solar radiation disturbances when using linear controllers. Moreover, it significantly contributes to preserving the validity of the assumed linear description of the plant over its operation range. The FF input signal is a temperature set-point from GS-GPC control, while the control output is the oil flow-rate $q_{f f}$ which is computed by the lumped parameter description (Camacho et al., 1992):

$$
q_{f f}=\frac{K_{o p t} n_{o} S I-H_{l} S\left(T_{\text {mean }}-T_{a}\right)}{P_{c p}\left(T_{r e f}-T_{i n}\right)}
$$

The control algorithm works as follows: the GS-GPC receives the temperature set-point for the solar field and the current mean temperature and computes a virtual reference temperature, $T_{r e f}$, for the FF. The FF computes oil flow taking into account the virtual reference and the measured disturbances to track the desired set-point. Since the GS-GPC + FF scheme is considering a global model for one loop, the calculated flow-rate is for one loop (Sánchez et al., 2018a). The applied final flow-rate to the solar plant is $q f f$ multiplied the number of loops (all loops receives the same amount of HTF since the loop valves are normally used to equilibrate the flows in the loops).

\section{Event based GS-GPC for electric power refer- ence tracking}

Sometimes, the solar plant may receive an order for power limitation by the TSO, generally, due to a high sat- uration of the electrical grid. Upon receiving the order, the plant is obligated to reduce its net power injected into the electricity grid. In order to fulfill the power constraint, the plant will have time to comply with the TSO command. This is achieved by decreasing the flow-rate and, in general, this is a complex operation for the operator.

In this work an Event based GS-GPC (EGS-GPC) is applied to control the electric power generated by the plant (Sánchez et al., 2018a). An event detection system will be responsible for activating the control strategy of the net power generated when power limitations are imposed. Although the power cycle is not linear and depends on the flow-rate, at nominal temperature it can be approximated as a first-order system with different time constants depending on the oil flow-rate (Schenk et al., 2015; Montañés et al., 2018). Since this situation generally occurs in saturation, nominal operating conditions are assumed.

$$
G=\frac{b_{0} z^{-} 1}{1+a_{0} z^{-1}}
$$

Table 2

PW Linear model parameters depending on flow $\left(\mathrm{m}^{3} / \mathrm{h}\right)$

\begin{tabular}{llll}
\hline $\mathrm{Q}$ & 855 & 1710 & 2565 \\
\hline$b_{0}$ & 0.01385 & 0.009328 & 0.006185 \\
\hline$a_{0}$ & -0.8382 & -0.891 & -0.9277 \\
\hline
\end{tabular}

The operating range of the EGS-GPC, in this mode of operation, has been divided into 3 flow-rate points: 167.06, 334.1 and $501.16 \mathrm{~kg} / \mathrm{s}\left(855,1710\right.$ and $\left.2565 \mathrm{~m}^{3} / \mathrm{h}\right)$. The GS will consist of the linear models obtained at these three working points. The discrete-time transfer functions have been chosen as indicated in Eq. (12) and Table 2 shows the parameter of linear models for the considered HTF flow-rate operating point. Refer to Sánchez et al. (2018a) for full details.

When a power limitation is received by the TSO, the control strategy is switched from the temperature tracking GS-GPC to the power tracking GS-GPC. Boolean variables will manage the event detection system by activating it or deactivating when receiving power limitations. The time required to reach the power limitation is taken into account in the power GS-GPC by taking advantage of the use of the sliding horizon. In this way it is possible to create time ramp power set-points (future set-points). This will make better and smoother power set-point tracking than with a simple power step. When the TSO removes the power limitation, the power GS-GPC will start the power up-ramp to reach nominal conditions. The control is switched from power tracking to temperature tracking if the nominal power is reached or if it is not possible to reach it due to low field outlet temperature.

\section{Fourth and third collector defocus MPC}

Parabolic trough plants have a safety mechanism to prevent the temperature of the loops from exceeding the 
optimum thermal limits of the HTF. This is done by defocusing the collectors, thus modifying the angle of the collector. The defocusing of the fourth collector is generally applied to prevent the oil temperature from exceeding a maximum temperature $\left(400^{\circ} \mathrm{C}\right)$. However, a control based on threshold causes oscillations in the outlet temperature.

Generally, the defocusing action of the fourth collector is, in normal situations, sufficient to control the outlet temperature around a set-point, avoiding exceeding the established thermal limit. However, when power limitations appear, defocusing the fourth collector is not enough to avoid exceeding the safe thermal limit of the HTF, and the third collector defocus has to be applied. In a previous work (Sánchez et al. (2018a)) a GS-GPC was developed for the defocusing of the fourth and third collectors. This strategy was based on linear models for different flowrates and defocus angles (due to the non-linear nature of the defocus curve, see Fig 2). The GS-GPC showed good performance at controlling the temperature. However, its performance may be affected due to the fact that it is based on linear transfer functions and does not take into account all the parameter variations at the different working points.

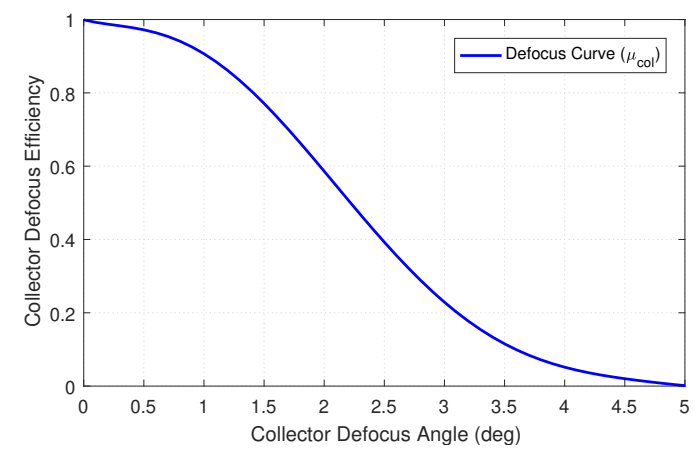

Figure 2 Efficiency - Defocus angle curve.

In this section, the adaptive incremental state-space MPC is presented. The proposed strategy is applied to control the defocus angle of the fourth and third collectors. Since the MPC makes use of the state, the distributed parameter model in equation (4) will be used for its calculation. To avoid high computing times and maintain a good level of similarity with the non-linear model, the collectors have been divided into 5 segments. Since the only measurable temperature states are the inlet temperature and the outlet temperature of the fluid, it is necessary to include estimation of the intermediate states by an observer. This is achieved using an unscented Kalman filter (UKF). The overall optical efficiency of the collector is also estimated. In plants with a large number of collectors, the overall optical efficiency of the collectors can vary. Performing defocus control with unrealistic values may result in inefficient control actions. For the estimation of this parameter, the lumped parameter model in equation (6) is used. The defocus curve and temperatures set-points for the MPC defocus strategy are detailed in subsection 5.5.

\section{1. $M P C$ formulation}

The linear state space model is an approximation of the PDE system (4), consisting of a set of matrices depending on inputs and system states. Let $x_{t}$ be the state vector formed by the temperatures of the 5 metal and fluid segments. The manipulated variable is $\mu_{c o l}$, which is the collector defocus efficiency. This variable is converted into degrees by using the defocusing curve, Fig 2, producing the values of the defocus degrees to be applied to the collectors, $\gamma$ and $\beta$ in Fig. 5 .

The linear model in continuous time is computed using Eq. (13). $T_{i n}$ is the inlet temperature, $q$ is the HTF flowrate and $T_{a}$ the ambient temperature. $\Delta l$, Eq. (14), is the length of each segment in which the metal tube is broken down $(30 \mathrm{~m})$. In order to reduce the complexity of the control strategy and the computational burden due to high order matrices, a segment length of $30 \mathrm{~m}$ is used instead of the $2 \mathrm{~m}$ length of the simulation model. $I_{\text {eff }}=I K_{\text {opt }} n_{o}$ is the effective solar radiation, Eq. (18).

$$
\begin{aligned}
& \dot{x}_{t}=A x_{t}+B u_{t}+B_{d} d_{t} \\
& y_{t}=C x_{t} \\
& u_{t}=\mu_{c o l} \quad d_{t}=\left[q T_{i n} T_{a}\right]^{T}
\end{aligned}
$$

The model matrices are calculated as follows:

$$
\begin{aligned}
P_{0} & =\frac{-H_{l} G-L H_{t}}{\rho_{m} C_{m} A_{m}} & P_{3}=\frac{q}{A_{f} \Delta l} \\
P_{1} & =\frac{L H_{t}}{\rho_{m} C_{m} A_{m}} & P_{4}=-P_{2}-P_{3} \\
P_{2} & =\frac{L H_{t}}{\rho_{f} C_{f} A_{f}} &
\end{aligned}
$$

$$
A=\left[\begin{array}{cccccccccc}
P_{0} & 0 & 0 & 0 & 0 & P_{1} & 0 & 0 & 0 & 0 \\
0 & P_{0} & 0 & 0 & 0 & 0 & P_{1} & 0 & 0 & 0 \\
\cdots & \cdots & \cdots & \cdots & \cdots & \cdots & \ldots & \cdots & \cdots & \cdots \\
0 & 0 & 0 & 0 & P_{0} & 0 & 0 & 0 & 0 & P_{1} \\
P_{2} & 0 & 0 & 0 & 0 & P_{3} & 0 & 0 & 0 & 0 \\
0 & P_{2} & 0 & 0 & 0 & P_{4} & P_{3} & 0 & 0 & 0 \\
\cdots & \ldots & \ldots & \cdots & \ldots & \ldots & \ldots & \ldots & \ldots & \ldots \\
0 & 0 & 0 & 0 & P_{2} & 0 & 0 & 0 & P_{4} & P_{3}
\end{array}\right]
$$

The first 5 state variables are the metal tube temperatures. The last 5 state variables correspond to the fluid (HTF) temperatures. As can be observed, signal $q$ appears in Matrix $A$, specifically in term $P_{3}$. It defines the operating point of the nonlinear model linearization.

The disturbance matrices, $B_{q}, B_{T i n}$ and $B_{T a}$, are computed as follows: 


$$
\begin{aligned}
& B=\left[\begin{array}{llll}
\frac{G I_{\text {eff }}}{\rho_{m} C_{m} A_{m}} & \cdots & \frac{G I_{\text {eff }}}{\rho_{m} C_{m} A_{m}} & 0_{1 x 5}
\end{array}\right]^{\top} \\
& B_{q}=\left[\begin{array}{llll}
0_{1 x 5} & \frac{1}{A_{f} \Delta l} & \cdots & \frac{1}{A_{f} \Delta l}
\end{array}\right]^{\top} \\
& B_{\text {Tin }}=\left[\begin{array}{lll}
0_{1 x 5} & \frac{q}{A_{f} \Delta l} & 0_{1 x 4}
\end{array}\right]^{\top} \\
& B_{T a}=\left[\begin{array}{llll}
\frac{H_{l} G}{\rho_{m} C_{m} A_{m}} & \cdots & \frac{H_{l} G}{\rho_{m} C_{m} A_{m}} & 0_{1 x 5}
\end{array}\right]^{\top} \\
& B_{d}=\left[\begin{array}{lll}
B_{q} & B_{T i n} & B_{T a}
\end{array}\right] \\
& C=\left[\begin{array}{llllllllll}
0 & 0 & 0 & 0 & 0 & 0 & 0 & 0 & 0 & 1
\end{array}\right]
\end{aligned}
$$

It is important to stress that only parameters $\rho_{m}, C_{m}$, $A_{f}, A_{m}$ and $G$ are constants. As has been mentioned before, $p_{f}, C_{f}, H_{l}$ and $H_{t}$ depend on the states (temperatures). These parameters are computed at the operating point at which the plant is working at each sampling time. Notice that matrix $A$ depends on the system states, parameters and oil flow-rate; $B_{T a}$ is function of the states and parameters and $B_{\text {Tin }}$ depends on the oil flow-rate. To compute the MPC strategy the linear matrices are discretized using a sample time of 30 seconds.

As far as the sampling time is concerned, it was found that adequate control sampling times are within the range of 15-40 seconds according to the dynamics of the system (Sánchez et al., 2018a). Faster sampling times allow faster reactions but the high frequency dynamics of the system may be excited (Álvarez et al., 2010). This effect can be seen in section 6 , where the high frequency dynamics of the plant are excited when the controller is too demanding. Furthermore, in order to preserve the actuator life, abrupt and frequent changes in the control action are not desirable. In this paper, a control sampling time of $30 \mathrm{~s}$ has been chosen. This sampling time avoids excessively brisk control actions while maintaining adequate performance.

Generally, the mathematical formulation of the MPC problem is posed as follows:

$$
\begin{aligned}
\min _{\Delta u} J= & R_{y} \sum_{t=1}^{N_{p}}\left(y_{k+t \mid k}-y_{k+t}^{r e f}\right)^{\top}\left(y_{k+t \mid k}-y_{k+t}^{r e f}\right) \\
& +R_{u} \sum_{t=0}^{N_{c}-1} \Delta u_{k+t \mid k}^{\top} \Delta u_{k+t \mid k}
\end{aligned}
$$

$$
\begin{aligned}
& \text { s.t. } \\
& y_{k+t \mid k}=f\left(\Delta u, y_{k+t-1}, y_{k+t-2}, \ldots\right) \\
& u_{k+t \mid k}=u_{k+t-1 \mid k}+\Delta u_{k+t \mid k} \\
& u_{\min } \leq u_{k+t \mid k} \leq u_{\max }
\end{aligned}
$$

where $f\left(\Delta u, y_{k+t-1}, y_{k+t-2}, \ldots\right)$ is the function used to compute the future evolution of the system. $N_{p}$ and $N_{c}$ stand for the prediction and the control horizons respectively. The parameter $R_{y}$ penalizes the tracking error and $R_{u}$ penalizes the control effort. Then $u_{k} \equiv u_{k \mid k}$ is applied to the system. In this case, only constraints in the amplitude of the efficiency have been considered. The changes of the parameters of the solar plant model used by the controller adapt the controller to the changing situations. The general control parameters of the controller (horizons and weights) are not changed. The control tuning values selected are, $R_{y}=1, R_{u}=700, N_{p}=12$ and $N_{c}=6$. When solving the MPC the values of $T_{i n}, T_{a}$ and $I_{\text {eff }}$ are kept constant along the prediction horizon (persistence method) due to their stochastic nature and the difficulty of modeling these disturbances.

\subsection{Incremental state space $M P C$ formulation}

In this subsection, the incremental state-space formulation is presented.

A drawback of using a state-space formulation in model predictive control strategies is that steady-state errors may appear due to modeling mismatches. One of the possible solutions is using disturbance estimators at the cost of having additional dynamics and parameters to be adjusted (Maeder et al., 2009; Limon et al., 2010).

The solution chosen in this paper is to use an incremental state-space formulation as explained in (di Ruscio, 2013). The advantage is that this formulation achieves offset-free responses when step references and step disturbances are considered. The formulation is only outlined since the complete explanation can be found in (di Ruscio, 2013).

Let's consider a general linear state-space model with $n$ inputs, $m$ outputs, $p$ states and $r$ disturbance sources:

$$
\begin{gathered}
x_{k+1}=A x_{k}+B u_{k}+B d_{d} \\
y_{k}=C x_{k}
\end{gathered}
$$

The state vector is augmented to include the output of the system. The incremental formulation is as follows:

$$
\begin{gathered}
\Delta x_{k+1}=A \Delta x_{k}+B \Delta u_{k}+B_{d} \Delta d_{k} \\
y_{k}=y_{k-1}+C \Delta x_{k}
\end{gathered}
$$

where $\Delta x_{k}=x_{k}-x_{k-1}$.

Considering (26) and (27), the complete state-space model is rewritten as follows:

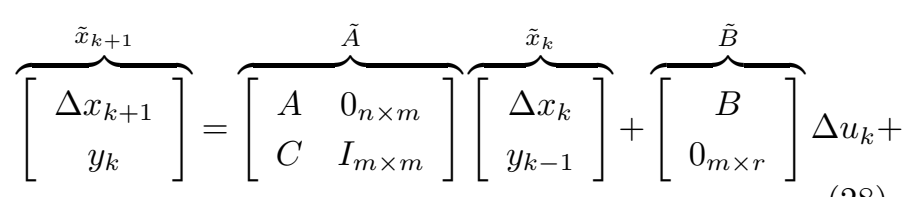

$$
\overbrace{\left[\begin{array}{c}
B d \\
0_{p \times r}
\end{array}\right]}^{\tilde{B d}} \Delta d_{k}
$$




$$
y_{k}=\overbrace{\left[\begin{array}{ll}
C & I_{m \times m}
\end{array}\right]}^{\tilde{C}}\left[\begin{array}{c}
\Delta x_{k} \\
y_{k-1}
\end{array}\right]
$$

The new matrices can now be included in the MPC algorithm to obtain the control signal at each sampling time. The free response of the system depends on the measurement of the output of the system, $y_{k-1}$, di Ruscio (2013). The new system can be formulated as follows:

$$
\begin{gathered}
\tilde{x}_{k+1}=\tilde{A} \tilde{x}_{k}+\tilde{B} \Delta u_{k}+\tilde{B} d \Delta d_{k} \\
y_{k}=\tilde{C} \tilde{x}_{k}
\end{gathered}
$$

Since the model used is linear, the predicted response of the system can be described by the sum of the forced response, a term which depends on the future control actions, and the free response which does not depend on the future control actions (Camacho and Bordons (2007)) as follows:

$$
y=G \Delta u+f
$$

where $G$ can be obtained from the model matrices (equations (31) and (32)) and the free response can be computed as a matrix depending on the past values of the states, outputs and measured disturbances. Since it is difficult to know how disturbances are going to evolve in the future, they are assumed to be constant along the prediction horizon. The free response can be calculated as follows (Camacho and Bordons, 2007):

$$
f=F\left[\begin{array}{c}
\Delta \tilde{x}_{k} \\
y_{k-1}
\end{array}\right]+G_{q} \Delta q+G_{T i n} \Delta T i n+G_{T a} \Delta T_{a}
$$

where matrix $F$ can be obtained from the model, and matrices $G_{q}, G_{T a}$ and $G_{T i n}$ are the contribution of each variable to the future evolution of the output.

\subsection{Nonlinear state estimator: the unscented Kalman fil- ter}

Since Rudolf Kalman presented his original work about optimal estimators (Kalman, 1960), the Kalman filter has been a widely used tool for state estimation in linear systems and then in nonlinear systems using extensions such as the extended Kalman filter (EKF) and the unscented Kalman filter (UKF) (Haykin, 2001).

The state space model considered in the MPC strategy uses the metal-fluid temperature profiles as the model states. Only the inlet and outlet fluid temperatures are measurable so that the intermediate fluid temperatures and metal temperatures have to be estimated. In this paper, a UKF is used to estimate the metal-fluid temperature segments. The nonlinear model used in the UKF is a simpler version of that described by equations (4), dividing the tube into 5 segments instead of the 75 used in the full nonlinear model used for simulation purposes. This simplification is used to reduce the computational burden and complexity of the control strategy. A greater number of segments considered would increase the number of the parameters to be adjusted in the covariance matrices, as shown in Gallego and Camacho (2012).

The UKF is based on the unscented transformation, which represents a method to calculate the mean and covariance of a random variable that undergoes a nonlinear transformation (Romanenko and Castro, 2004; St-Pierre and Gringras, 2004). Since the appearance of the UKF algorithm, several improvements and variations have been developed (Li et al., 2014; Zhou et al., 2015). In Wang et al. (2017), an improved unscented transformation by incorporating the random parameters into the state vector to enlarge the number of sigma points is proposed. For more details about the UKF implementation, the reader is referred to Haykin (2001).

Another important issue is the sampling time of the UKF estimator. In order to capture the dynamics of the temperature evolution, the UKF sampling time has been chosen as 10 seconds, since the control sampling time (30 seconds) is too long to capture the temperature evolution properly.

It was found that smaller sampling times did not produce any improvement in the estimation. Furthermore, smaller sampling times would be too demanding, since the computational time for 90 loops is about 4 seconds. Results of the fluid temperatures estimations are compared to the distributed parameters model (DPM) simulation in Fig. 3, showing good performance.

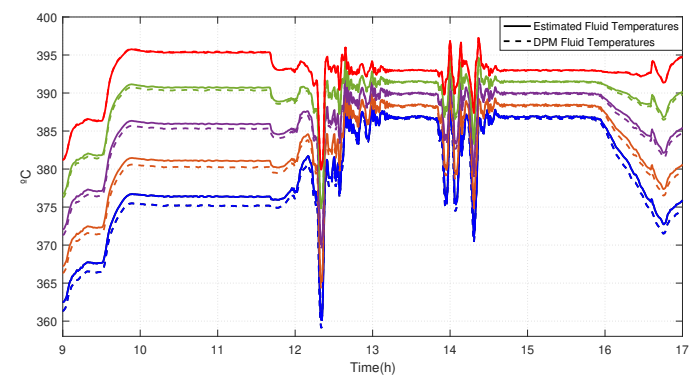

Figure 3 Collector fluid temperature estimation.

\subsection{LPM collector efficiency estimation}

In plants of considerable size such as $50 \mathrm{MW}$ plants (220 hectares, 360 collectors), the optical efficiency of the collectors may change. Given the dimensions, it is not efficient to approximate all loops by a collective average or unique value. Optical efficiency depends proportionally on the reflectivity, shape factor and efficiency of the receiver tube. Therefore, due to dust, wind, position of collectors and other environmental factors, not all loops will have the same optical efficiency. Since an adaptive strategy is being implemented, the estimation of collector efficiency is necessary to adjust the parameter of the linear model 
used in the MPC. The optical efficiency of each collector is estimated using the lumped parameter model (35).

$$
K_{\text {opt }}=\frac{C \frac{d T_{\text {out }}}{d t}+q P_{c p}\left(T_{o u t}-T_{\text {in }}\right)+H_{l} S\left(T_{\text {mean }}-T_{a}\right)}{n_{o} S I}
$$

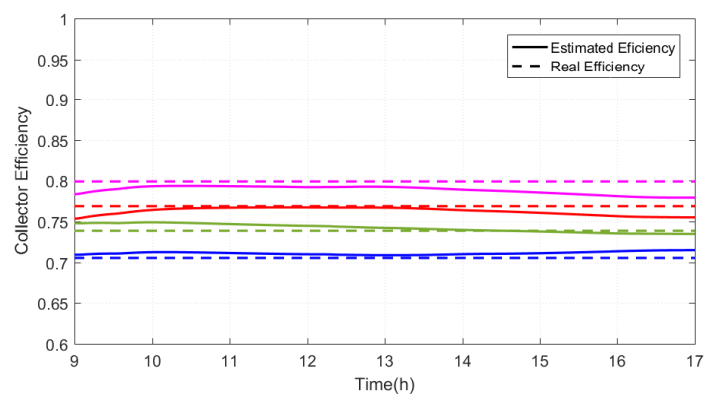

Figure 4 Collector efficiency estimation using the lumped parameter model.

Since it is a quasi-static parameter, its variation throughout the day is slow, the resulting estimate obtained with the lumped parameter model will be filtered to avoid false estimates in sudden changes due to the very nature of the lumped parameter model. Results presented in Fig. 4 show reasonably good performance at estimating the efficiency of a collector with a mean error of $0.02(2 \%)$ with respect to the real value of the efficiency being used in the simulation of the plant.

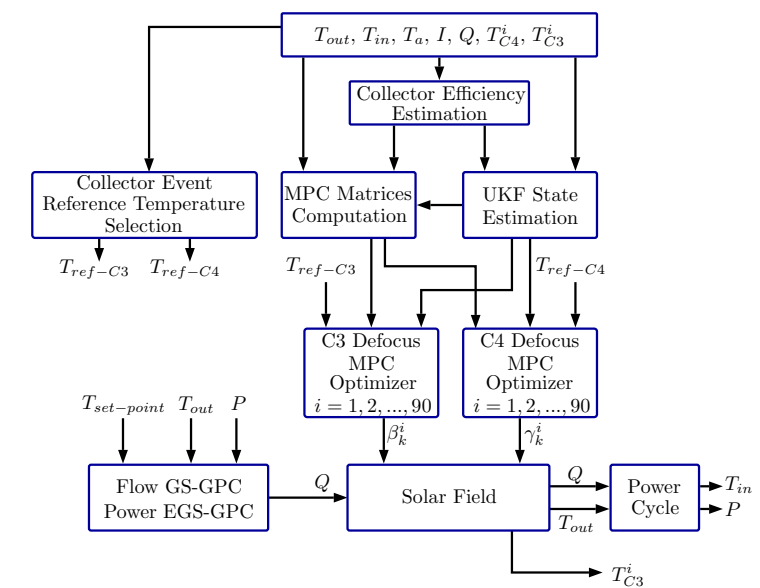

Figure 5 Flow/Power EGS-GPC + C4/C3 MPC control scheme.

\subsection{Defocus curve and tracking references}

A function that relates the defocus angle to collector efficiency is needed. An approximation of this function is presented in Fig. 2, (Goswami et al., 2000). From a certain defocus angle, efficiency begins to decrease rapidly, since rays no longer reach the receiver tube. As can be observed, the defocusing curve is non-linear. The curve has a steep slope around 2-3 degrees of defocus. Beyond 3 degrees, the efficiency approaches zero, which means very little control ability. The temperature set-point for the third collector has been chosen to be $385^{\circ} \mathrm{C}$ (Sánchez et al., 2018a).

Tracking references for the fourth collector defocus MPC are automatically applied by a set of rules. $393{ }^{\circ} \mathrm{C}$ and $396{ }^{\circ} \mathrm{C}$ temperatures $\left(T_{\text {ref-sat }}\right.$ and $\left.T_{\text {ref-nosat }}\right)$ references will be applied depending on the field outlet temperature, power limitation events and flow-rate. For a complete description of the rules the reader is referred to Sánchez et al. (2018a). The full control scheme is presented in Fig. 5.

\section{Results}

In this section, results from simulations are presented. Two scenarios have been simulated: (1) the plant receives a command to limit the power to $40 \mathrm{MW}$, and (2) the power limitation is $30 \mathrm{MW}$. These scenarios have been simulated to show the defocus angle needed in each case. In both scenarios, the proposed incremental MPC control strategy is compared to the GS-GPC control scheme. The GS-GPC has been fine tuned in order to have a fair comparison.

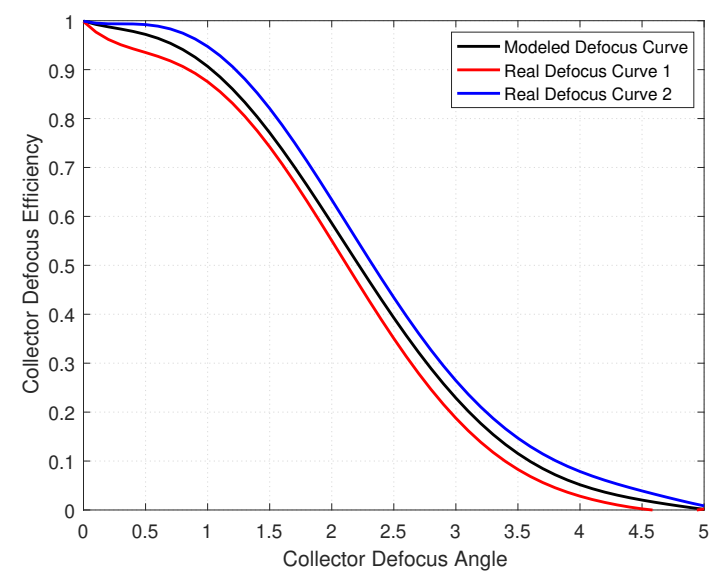

Figure 6 Efficiency - Defocus angle curve with modeling errors.

In order to show the capabilities of both strategies when there are modeling errors, different efficiency defocus curves have been applied. Fig. 6 presents 3 different defocusing curves. The curves applied to simulate the real efficiency of the collectors in respect to the defocus angle are the curves denoted as "Real Defocus Curve 1" and "Real Defocus Curve 2" in Fig 6. The "Modeled Defocus Curve" is that applied to the control strategy and the estimations. The RMSE for "Real Defocus Curve 1" is 0.7059, while for "Real Defocus Curve 2" is 0.7712. The error in the range of 1.5-3 degrees varies between a $10 \%$ to a $15 \%$ approximately in both curves respect to the modeled curve. Finally, to show the MPC improvements in the form of quantitative results, Integral Total Accumulated Error (ITAE) and Integral Square Error (ISE) performance indexes have been computed for all the simulated scenarios. The compared values are shown in Tables 3 and 4 . 


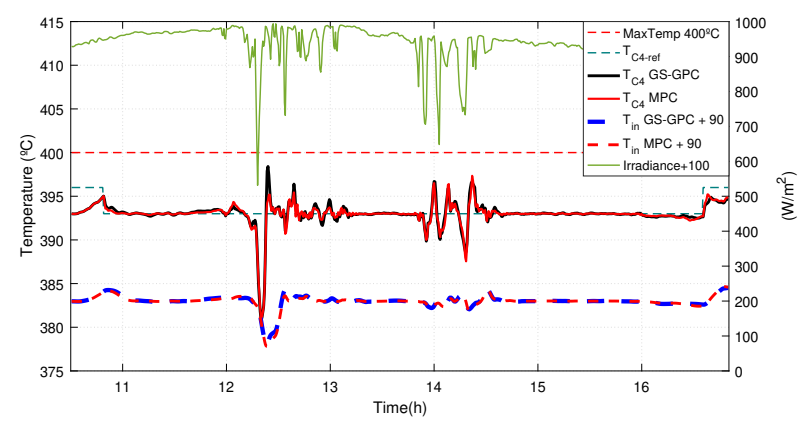

the GS-GPC when there are irradiance transients. In general, the MPC is capable of acting before the GS-GPC due to the state space formulation which can precisely simulate the fluid temperature transported to the output of the collectors. It can be seen that both strategies are performing similarly when there are modeling errors.
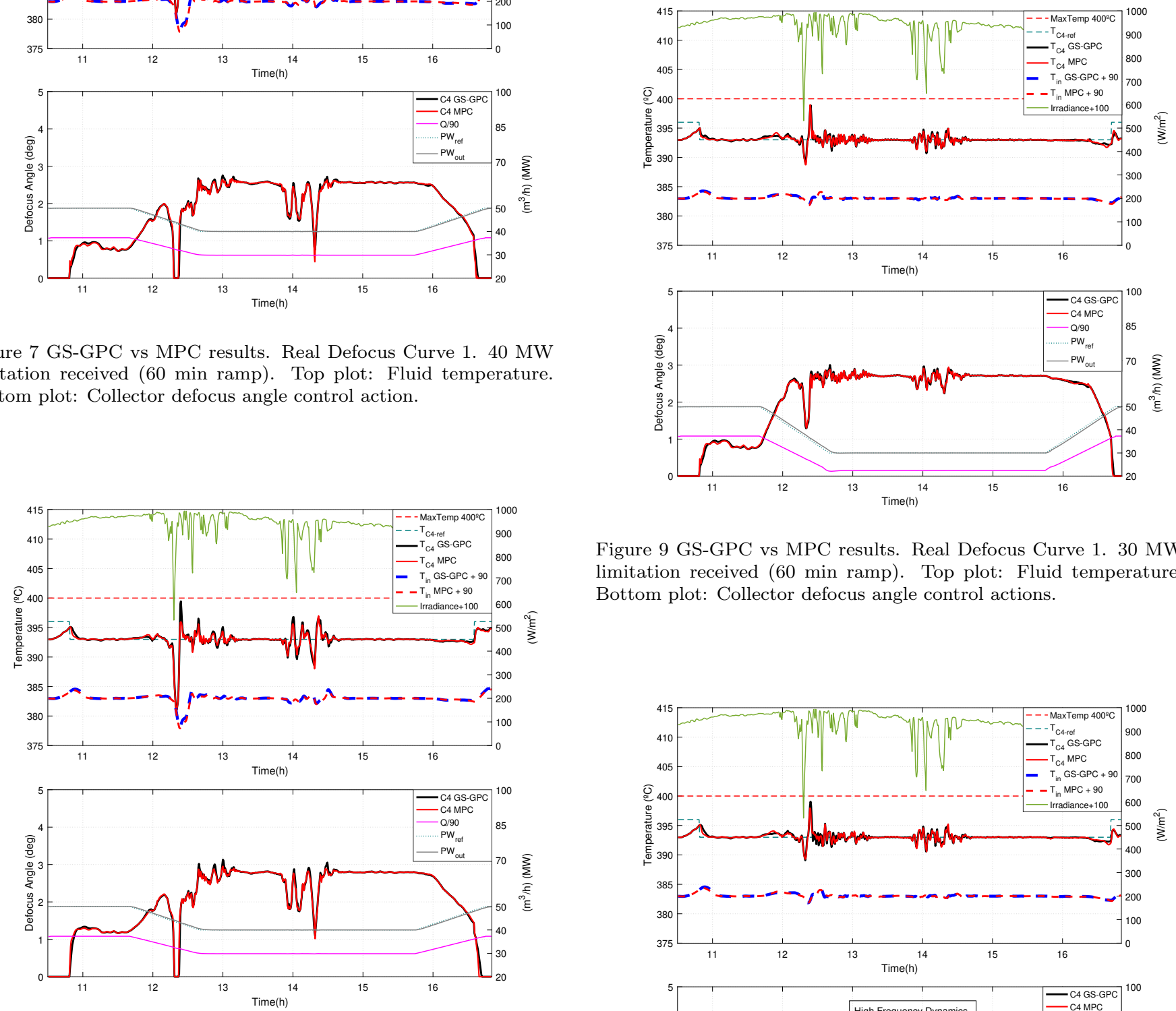

Figure 8 GS-GPC vs MPC results. Real Defocus Curve 2. $40 \mathrm{MW}$ limitation received (60 min ramp). Top plot: Fluid temperature. Bottom plot: Collector defocus angle control actions.

In Figs. 7 and 8, the simulated scenarios are $40 \mathrm{MW}$ power limitations when real defocus curves, "Real Defocus Curve 1" and "Real Defocus Curve 2", are applied to the simulation. The flow-rate shown in this section, $Q$, is the flow-rate of the plant which it can be either the flow-rate computed by the power GS-GPC or the computed flowrate by the Feed-Forward multiplied by 90 loops. It can be seen that the MPC control is able to perform better than

Figure 9 GS-GPC vs MPC results. Real Defocus Curve 1. $30 \mathrm{MW}$ limitation received (60 min ramp). Top plot: Fluid temperature. Bottom plot: Collector defocus angle control actions.
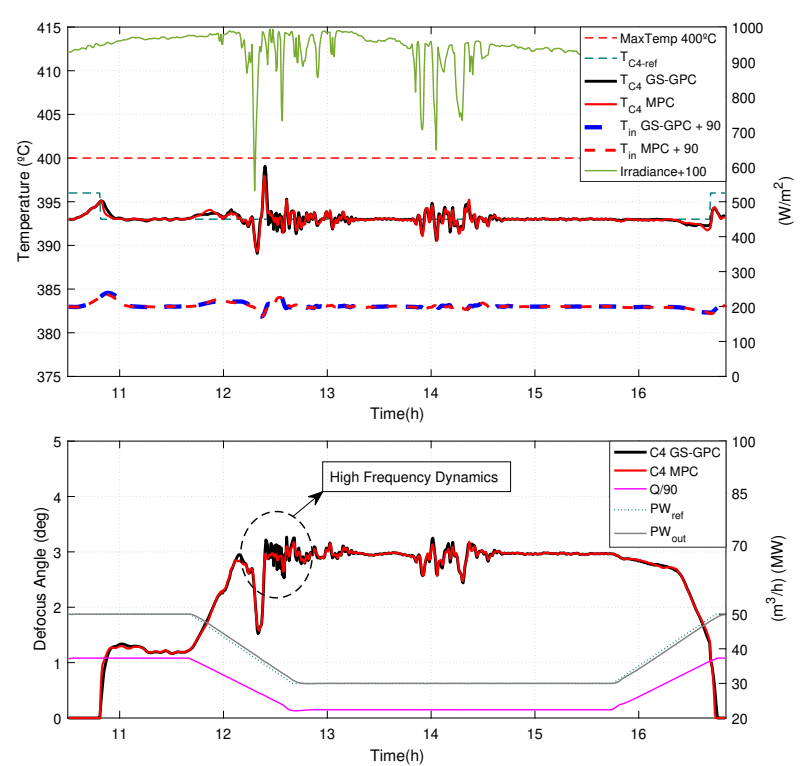

Figure 10 GS-GPC vs MPC results. Real Defocus Curve 2. $30 \mathrm{MW}$ limitation received (60 min ramp). Top plot: Fluid temperature. Bottom plot: Collector defocus angle control actions.

In Figs. 9 and 10, simulations for the $30 \mathrm{MW}$ scenarios 
are presented. As before, the simulated scenarios, "Real Defocus Curve 1" and "Real Defocus Curve 2" are used in the control strategies. It is possible to observe that both strategies are performing similarly, but as can be seen in Tables 3 and 4, the incremental MPC obtains improvements in both indexes.

Notice that in Fig. 10, the GS-GPC has been fine tuned up to the limit, in order to compare both strategies. Fig. 10 shows that, at this point, the GS-GPC is about to excite high frequency dynamics, see marked area. To emphasize the consequences of making the GS-GPC more reactive in order to achieve similar results, in Fig. 11 a simulation of the GS-GPC is shown. The high frequency dynamics excitation by the GS-GPC, see marked areas in Fig. 11, are now affecting the plant outlet temperature (oscillation pattern).
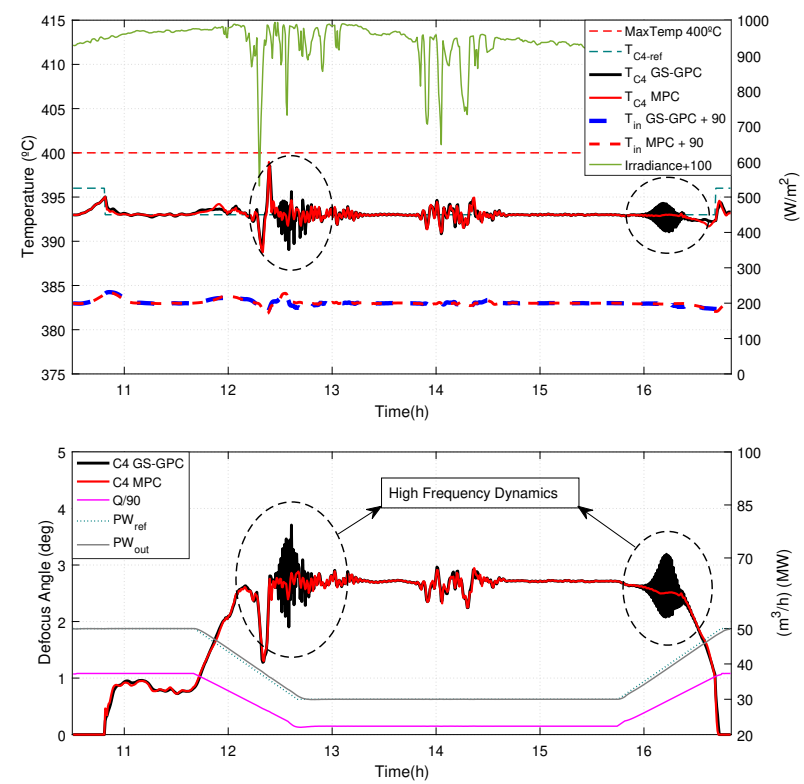

Figure 11 GS-GPC vs MPC results. Real Defocus Curve 2. GSGPC control exciting high frequency dynamics. Top plot: Fluid temperature. Bottom plot: Collector defocus angle control actions.

Tables 3 and 4 show that the behaviour of the MPC is better than that of the GS-GPC. From the ITAE point of view and depending on the scenario, the MPC improvement achieved goes from $2 \%$ up to a $15 \%$. The ISE index shows improvements from $7 \%$ to $16 \%$. From the ITAE index, it can be observed that the MPC has better performance in tracking and it is faster than the GS-GPC. The ISE also shows that the MPC has less oscillations than the GS-GPC since this index penalizes more this type of error.
Table 3

ITAE comparison $\left({ }^{\circ} \mathrm{C} \cdot \mathrm{s}\right)$.

\begin{tabular}{lccc}
\hline Scenario & ITAE GSGPC & ITAE MPC & Reduction(\%) \\
\hline $40 \mathrm{MW}$, Curve 1 & $9.0871 \times 10^{7}$ & $7.9772 \mathrm{e} \times 10^{7}$ & 12.2133 \\
\hline $40 \mathrm{MW}$, Curve 2 & $9.3993 \times 10^{7}$ & $7.9204 \times 10^{7}$ & 15.7341 \\
\hline $30 \mathrm{MW}$, Curve 1 & $4.9391 \times 10^{7}$ & $4.6249 \times 10^{7}$ & 6.3601 \\
\hline $30 \mathrm{MW}$, Curve 2 & $5.1933 \times 10^{7}$ & $5.0930 \times 10^{7}$ & 1.9309 \\
\hline
\end{tabular}

Table 4

ISE comparison $\left({ }^{\circ} \mathrm{C}^{2}\right)$

\begin{tabular}{lccc}
\hline Scenario & ISE GSGPC & ISE MPC & Reduction(\%) \\
\hline $40 \mathrm{MW}$, Curve 1 & $4.3276 \times 10^{4}$ & $3.9597 \times 10^{4}$ & 8.5016 \\
\hline $40 \mathrm{MW}$, Curve 2 & $4.5096 \times 10^{4}$ & $3.9381 \times 10^{4}$ & 12.6729 \\
\hline $30 \mathrm{MW}$, Curve 1 & $9.2271 \times 10^{3}$ & $8.5824 \times 10^{3}$ & 6.9869 \\
\hline $30 \mathrm{MW}$, Curve 2 & $10.535 \times 10^{3}$ & $8.776 \times 10^{3}$ & 16.6983 \\
\hline
\end{tabular}

Some final comments to end this section. It has to be highlighted that the GS-GPC has been fine tuned up to the limit and high frequency dynamics excitations have already been detected in the $30 \mathrm{MW}$ scenario, while the $\mathrm{MPC}$ is still performing without these excitations. Notice that it is always difficult to improve MPC control strategies that are already performing properly.

\section{Conclusions}

In this paper, an adaptive incremental state space MPC for defocusing the fourth and third collector has been proposed. The control strategy uses an Unscented Kalman filter to estimate the state temperatures and an estimator based on the lumped parameter model to obtain an estimation of the collector efficiencies. Moreover, the proposed MPC strategy has been compared to a GS-GPC control.

It has been proven that the proposed MPC strategy shows better performance and disturbances rejection than the GS-GPC. The MPC control is superior due to two main facts: (1) adaptive scheme and (2) incremental state space formulation. The GS-GPC has been fine tuned up to the limit in order to obtain a fair comparison. Moreover, the GS-GPC cannot be further adjusted due to high frequency dynamic excitation.

\section{Acknowledgments}

The authors would like to acknowledge the European Research Council for funding this work under Advanced Research Grant OCONTSOLAR (789051).

\section{References}

Alsharkawi, A., Rossiter, J. A., 2017. Towards an improved gain scheduling predictive control strategy for a solar thermal power plant. IET Control Theory Applications 11 (12), 1938-1947.

Alva, G., Liu, L., Huang, X., Fang, G., 2017. Thermal energy storage materials and systems for solar energy applications. Renewable and Sustainable Energy Reviews 68, 693 - 706 . 
Álvarez, J. D., Costa-Castelló, R., Berenguel, M., Yebra, L. J., 2010. A repetitive control scheme for distributed solar collector field. International Journal of Control 83 (5), 970-982.

Andasol 1, Sep. 2018.

URL https://solarpaces.nrel.gov/andasol-1

Blanco, M., Miller, S., 2017. 1 - introduction to concentrating solar thermal (cst) technologies. In: Blanco, M. J., Santigosa, L. R. (Eds.), Advances in Concentrating Solar Thermal Research and Technology. Woodhead Publishing Series in Energy. Woodhead Publishing, pp. $3-25$.

Blanco, M. J., Santigosa, L. R., 2017. Advances in Concentrating Solar Thermal Research and Technology, 1st Edition. Woodhead Publishing.

Burkholder, F., Brandemuehl, M., Price, H., Netter, J., Kutscher, C., Wolfrum, E., 2007. Parabolic trough receiver thermal testing. In: Energy Sustainability, ASME 2007 Energy Sustainability Conference. pp. 961-970.

Camacho, E., Gallego, A., 2013. Optimal operation in solar trough plants: A case study. Solar Energy 95, $106-117$.

Camacho, E. F., Berenguel, M., Rubio, F. R., 1994. Application of a gain scheduling generalized predictive controller to a solar power plant. Control Engineering Practice 2 (2), 227-238.

Camacho, E. F., Berenguel, M., Rubio, F. R., 1997. Advanced Control of Solar Plants. Springer Science \& Business Media.

Camacho, E. F., Bordons, C., 2007. Model Predictive control, 2nd Edition. Springer-Verlag London.

Camacho, E. F., Rubio, F. R., Hughes, F. M., April 1992. Self-tuning control of a solar power plant with a distributed collector field. IEEE Control Systems 12 (2), 72-78.

Camacho, E. F., Soria, M. B., Rubio, F. R., Martínez, D., 2012. Control of Solar Energy Systems, 1st Edition. Springer-Verlag London.

Carmona, R., 1985. Analisis, modelado y control de un campo de colectores solares distribuidos con sistema de seguimiento en un eje. Ph.D. thesis. Universidad de Sevilla.

Cojocaru, E. G., Bravo, J. M., Vasallo, M. J., Santos, D. M., 2019 Optimal scheduling in concentrating solar power plants oriented to low generation cycling. Renewable Energy 135, 789 - 799

Desai, N. B., Bandyopadhyay, S., 2015. Optimization of concentrating solar thermal power plant based on parabolic trough collector. Journal of Cleaner Production 89, $262-271$.

di Ruscio, D., 2013. Model predictive control with integral algorithm: A simple mpc algorithm. Modeling, Identification and Control 34 (3), 119-129.

Elias, T. A., Mendes, P. C., Normey-Rico, J. E., Alba, C. B., 2018 Optimal solar collectors defocusing based on maximum temperature. In: 9th International Renewable Energy Congress (IREC), Hammamet, Tunisia.

Extresol-1, Sep. 2018.

URL https://solarpaces.nrel.gov/extresol-1

Gallego, A., Camacho, E., 2012. Adaptative state-space model predictive control of a parabolic-trough field. Control Engineering Practice 20 (9), $904-911$.

Geyer, M., Lüpfert, E., Osuna, R., Esteban, A., Schiel, W. Schweitzer, A., Zarza, E., Nava, P., Langenkamp, J., Mandelberg, E., Sep. 2002. Eurotrough - parabolic trough collector developed for cost efficient solar power generation. In: 11th SolarPACES International Symposium on Concentrated Solar Power and Chemical Energy Technologies.

Gil, P., Henriques, J., Cardoso, A., Carvalho, P., Dourado, A., March 2014. Affine neural network-based predictive control applied to a distributed solar collector field. IEEE Transactions on Control Systems Technology 22 (2), 585-596.

Goswami, D., Kreith, F., Kreider, J., 2000. Principles of Solar Engineering., 2nd Edition. Taylor \& Francis.

Guzmán, Sep. 2018. URL https://solarpaces.nrel.gov/guzman

Haykin, S., 2001. Kalman Filtering and Neural Networks. A WileyInterscience Publication.

He, G., Chen, Q., Kang, C., Xia, Q., Jul. 2016. Optimal offering strategy for concentrating solar power plants in joint energy, reserve and regulation markets. IEEE Transactions on Sustainable
Energy 7 (3), 1245-1254

Helios I, Sep. 2018

URL https://solarpaces.nrel.gov/helios-i

Ibersol Ciudad Real, Sep. 2018. URL

ibersol-ciudad-real-puertollano

Kalman, R., 1960. A new approach to linear filtering and predictions problem. Trans. ASME Jounal of Basic Engineering 82, 35-60.

Kaxu Solar One, Sep. 2018.

URL https://solarpaces.nrel.gov/kaxu-solar-one

Kearney, D. W., 2007. Parabolic trough collector overview. Parabolic trough work-shop, NREL.

Khoukhi, B., Tadjine, M., Boucherit, M. S., May 2015. Nonlinear continuous-time generalized predictive control of solar power plant. Int. J. Simul. Multisci. Des. Optim. 6.

Li, L., Hua, C., Yang, H., 2014. A new adaptive unscented kalman filter based on covariance matching technique. In: International Conference on Mechatronics and Control (ICMC).

Lima, D. M., Normey-Rico, J. E., Santos, T. L. M., 2016. Temperature control in a solar collector field using filtered dynamic matrix control. ISA Transactions 62, 39 - 49, sI: Control of Renewable Energy Systems.

Limon, D., Alvarado, I., Alamo, T., Camacho, E., 2010. Robust tube-based mpc for tracking of constrained linear systems with additive disturbances. Journal of Process Control 20, 248-260.

Liu, M., Tay, N. S., Bell, S., Belusko, M., Jacob, R., Will, G., Saman, W., Bruno, F., 2016. Review on concentrating solar power plants and new developments in high temperature thermal energy storage technologies. Renewable and Sustainable Energy Reviews 53, 1411 $-1432$.

Lüpfert, E., Riffelmann, K., Price, H., Burkholder, F., Moss, T., May 2008. Experimental analysis of overall thermal properties of parabolic trough receivers. Journal of Solar Energy Engineering $130(2)$

Maeder, U., Borrelli, F., Morari, M., 2009. Linear offset-free model predictive control. Automatica 45, 2214-2222.

Majadas I, Sep. 2018.

URL https://solarpaces.nrel.gov/majadas-i

Mojave Solar Project, Sep. 2018.

URL https://solarpaces.nrel.gov/mojave-solar-project

Montañés, R. M., Windahl, J., Palsson, J., Thern, M., 2018. Dynamic modeling of a parabolic trough solar thermal power plant with thermal storage using modelica. Heat Transfer Engineering 39 (3), 277-292.

N.A Engineering, 2008. National academy of engineering. grand challenges for engineering.

URL www.engineeringchallenges.org

Palma del Río I, Sep. 2018.

URL https://solarpaces.nrel.gov/palma-del-rio-i

Pelay, U., Luo, L., Fan, Y., Stitou, D., Rood, M., 2017. Thermal energy storage systems for concentrated solar power plants. Renewable and Sustainable Energy Reviews 79, 82 - 100.

Roca, L., Bonilla, J., Rodríguez-García, M. M., Palenzuela, P., de la Calle, A., Valenzuela, L., 2016. Control strategies in a thermal oil molten salt heat exchanger. AIP Conference Proceedings 1734 (1), 130017

Rohani, S., Fluri, T., Dinter, F., Nitz, P., 2017. Modelling and simulation of parabolic trough plants based on real operating data. Solar Energy 158, $845-860$.

Romanenko, A., Castro, J. A., 2004. The unscented Kalman filter as an alternative to the EKF for nonlinear state estimation: a simulation case study. Computers and Chemical Engineering 28, 347-355.

Sánchez, A. J., Gallego, A. J., Escaño, J. M., Camacho, E. F., Nov. 2018a. Event-based mpc for defocusing and power production of a parabolic trough plant under power limitation. Solar Energy 174, $570-581$.

Sánchez, A. J., Gallego, A. J., Escaño, J. M., Camacho, E. F., May 2018b. Temperature homogenization of a solar trough field for performance improvement. Solar Energy. 165C, 1-9.

Sarbu, I., Sebarchievici, C., Jan. 2018. A comprehensive review of 
thermal energy storage. Sustainability 10 (1), 1-32.

Schenk, H., Dersch, J., Hirsch, T., Polklas, T., Sep. 2015. Transient simulation of the power block in a parabolic trough power plant. In: The 11th International Modelica Conference Versailles, France. Linköping University Electronic Press, Linköpings universitet, pp. 605-614.

SCHOTT Solar CSP GmbH, Sep. 2018. Schott ptr@70 receivers. URL https://www.us.schott.com/csp/english/ schott-solar-ptr-70-receivers.html

Solaben 2, Sep. 2018.

URL https://solarpaces.nrel.gov/solaben-2

Solana Generating Station, Sep. 2018.

URL

https://solarpaces.nrel.gov/

solana-generating-station

St-Pierre, M., Gringras, D., 2004. Comparison between the unscented kalman filter and the extended kalman filter for the position estimation module of an integrated navigation information system. IEEE Intelligent Vehicles Symposium 0-7803-8310-9/04, 831-835.

System Advisor Model (SAM). NREL, Sep. 2018.

URL https://sam.nrel.gov/

Termesol 50, Sep. 2018.

URL https://solarpaces.nrel.gov/termesol-50

Therminol VP1 HTF, Sep. 2018.

URL https://www . therminol.com/products/Therminol-VP1

Vasallo, M. J., Bravo, J. M., 2016. A mpc approach for optimal generation scheduling in csp plants. Applied Energy 165, 357 370.

Wang, Y., Qiu, Z., Qu, X., 2017. An improved unscented kalman filter for discrete nonlinear systems with random parameters. Discrete Dynamics in Nature and Society, 1-10.

Zhou, Y., Zhang, C., Zhang, Y., Zhang, J., 2015. A new adaptive square-root unscented kalman filter for nonlinear systems with additive noise. International Journal of Aerospace Engineering, $1-10$. 